\begin{tabular}{l}
\hline \hline OPEN \\
JOURNAL \\
SYSTEMS \\
\hline \hline ISSN:2237-2202
\end{tabular}

Available on line at Directory of Open Access Journals

Journal of Hyperspectral Remote Sensing v.9, n.6 (2019) 320-329

www.periodicos.ufpe.br/revistas/jhrs

\section{Journal of Hyperspectral Remote Sensing}

www.ufpe.br/jhrs

\title{
Degradation of the Vila Maria Spring in Garanhuns-PE
}

\author{
João Vitor de A. Bezerra*, Jeisiane S. Andrade**, Felippe P. de Melo**, Ricardo B. Vigoderis ${ }^{* * * *}$, Josiclêda D. \\ Galvíncio $^{* * * *}$, Werônica M. de Souza ${ }^{* * * * *}$ \\ *Mestrando em Ciências Ambientais - PPCIAM, Unidade Acadêmica de Garanhuns/Universidade Federal Rural de Pernambuco \\ (UAG/UFRPE), Garanhuns-PE, Brasil. E-mail: j.vitor.almeida@outlook.com. (autor correspondente) \\ ** Graduada em Engenharia Civil, Faculdade de Ciências Humanas e Sociais (UniAGES) \\ ****Professor Doutor, Departamento de Geografia, UniAGES. \\ ***** Professor Doutor, UAG/UFRPE, Garanhuns-PE, Brasil \\ *******ofessora Doutora, Universidade Federal de Pernambuco, Recife-PE, Brasil \\ ******* Professora Doutora, UAG/UFRPE, Garanhuns-PE, Brasil
}

Received 21 August 2019; accepted 31 October 2019

\begin{abstract}
This research aimed to analyze the degradation of the Vila Maria spring, located in the Magano neighborhood in the municipality of Garanhuns in the state of Pernambuco. The municipality's terrain is marked by undulated landform, especially hills, which allied to the accelerated rhythm of urban expansion without adequate planning, resulted in the occupation of risk areas such as slopes as well as environmental protection areas such as the adjacencies of springs. The analysis was carried out through a terrain modeling process in a geoprocessing environment and by data collected on visits to the study area. An analysis of the region's NDVI from years 2008 to 2018 was also performed. The analysis confirmed the Vila Maria spring's water degradation and found that it was aggravated by an inadequate disposal of rainwater through surface water drains which contributed to the intensification of erosive processes that generated a gully in the vicinity. The NDVI analysis found low average values with an increase from 2008 to 2018 during the wet season. This fact can be explained by the constant urban expansion which as has been utilizing slopes from the microbasin for the disposal of rainwater which allied to the constant flow of the Vila Maria spring, provides a constant supply of water to the vegetation cover. Moreover, it was possible to observe the misuse of the spring's water flow by the public administration which has most of its flow integrated to the surface water drainage system and it is disposed at the bottom of the slope going through a high risk of contamination.
\end{abstract}

Keywords: NDVI, remote sensing, geotechnologies.

\section{Degradação da Nascente Vila Maria na cidade de Garanhuns-PE}

\section{Resumo}

O presente trabalho objetivou analisar a degradação da Nascente Vila Maria, localizada no Bairro do Magano no Município de Garanhuns no estado de Pernambuco. O relevo do município é marcado por geoformas onduladas, principalmente colinas, que aliado ao ritmo acelerado de expansão urbana sem planejamento adequado, acarretou na ocupação de áreas de risco como encostas assim como locais que deveriam ser de proteção ambiental como as adjacências de nascentes. A análise foi realizada a partir de uma modelagem do relevo no ambiente do geoprocessamento e por informações coletadas em visitas ao local. Um levantamento do NDVI da região dos anos de 2008 até 2018 também foi realizado. A análise constatou a degradação hídrica da nascente agravada por um descarte inadequado do esgoto pluvial que contribuiu na intensificação dos processos erosivos que geraram uma voçoroca nas imediações. O levantamento do NDVI evidenciou valores médios baixos com um aumento entre os anos 2008 e 2018 durante os tempos chuvosos. Esse fato pode ser explicado pela constante expansão da poligonal urbana que vem utilizando as vertentes da microbacia para o descarte de escoamento pluvial que aliado ao fluxo contínuo da nascente, fornece um abastecimento de água constante para a cobertura vegetal. Ademais, constatou-se o mal aproveitamento do fluxo da nascente pela gestão pública que tem a maior parte do seu fluxo integrado ao esgoto pluvial e descartado no fundo da vertente correndo alto risco de contaminação.

Palavras-Chave: NDVI, sensoriamento remoto, geotecnologias. 


\section{Introdução}

A partir do instante em que o homem passou a exercer moradia fixa ele passou também a manipular a natureza e seus recursos, e, com o passar da evolução dos grupos, mais tarde chamados de sociedade(s), tais práticas foram se expandindo gradativamente ao ponto em que a exploração dos recursos naturais não mais refletiam uma necessidade de alimentação e sobrevivência da espécie, mas sim uma forma de acumulo de capital monetário.

Os hídricos, que representam uma parte significativa desses recursos explorados, exercem grande influência de diferentes maneiras ao redor do mundo. Nos locais com baixas precipitações, que possuem climas áridos ou semiáridos, a água é o "ouro" da população, chegando até mesmo a ser comercializada a valores exorbitantes.

A água, recurso considerado abundante em grande parte do território nacional, é escassa no semiárido brasileiro que há muitos anos convive com o estigma da seca, citando como consequências a alta mortalidade da sua população e os movimentos migratórios.

Embora haja a crença de falta de água no Nordeste por causa dos baixos índices de pluviosidade, a existência de lençóis subterrâneos na região se apresenta como contraponto a essa realidade, pois a quantidade de rios espalhados pelos mais diversos ambientes revelam a existência de bacias hidrográficas por praticamente em todo o seu domínio geográfico. Contudo, grande parte das nascentes, especialmente aquelas localizadas em sítios urbanos, estão contaminadas ou impermeabilizadas, o que traz à tona a má gestão dos recursos hídricos na região.

Além da contaminação, possíveis alterações na vazão das nascentes são consequências da ocupação urbana que podem significar o desaparecimento da nascente ou sua transformação em nascente temporária (Felippe e Magalhães Junior, 2012).

Conforme Felippe e Magalhães Junior (2013) não há um consenso na literatura especializada sobre o conceito de nascentes e cada pesquisador utiliza a definição mais conveniente para seu estudo. Entretanto, tal método pode acarretar em enganos e desentendimentos na comparação dos resultados de diferentes trabalhos. Sendo assim, os Autores supracitados propõem que as nascentes sejam consideradas como um sistema ambiental em que o afloramento da água subterrânea ocorre naturalmente, de modo temporário ou perene, e cujos fluxos hidrológicos na fase superficial são integrados a rede de drenagem.
Para a Lei Federal $\mathrm{N}^{\circ} 12.651$, de 25 de maio de 2012 o conceito de nascente é: afloramento natural do lençol freático que apresenta perenidade e dá início a um curso d'água (BRASIL, 2012).

Nascentes são elementos essenciais do ciclo hidrológico sendo vitais para o desenvolvimento cultural, econômico e tecnológico da sociedade. A relevância da sua proteção é evidenciada pelos marcos legais brasileiros (Carmo et al., 2014). São formadas quando um aquífero atinge a superfície e passa a propagar a água armazenada no subsolo e são influenciadas por diversos fatores como clima, cobertura vegetal, topografia, geologia e a forma de uso e ocupação de suas adjacências (Lozinski et al., 2010).

As nascentes podem ser classificadas quanto ao seu regime de água, sendo perenes quando apresentam fluxo contínuo; temporárias caso o fluxo ocorra apenas durante a estação de chuvas e efêmeras quando surgem durante uma chuva e permanecem somente por alguns dias ou horas (Calheiros et al., 2009).

Quanto ao grau de conservação, Pinto (2003) classificou as nascentes como preservadas, perturbadas e degradadas. As que apresentam um mínimo de 50 metros de vegetação natural em seu entorno sem sinais de perturbação ou degradação são classificadas como preservadas. Perturbadas são as nascentes que não possuem o mínimo de vegetação de 50 metros, porém, encontram-se em bom estado de conservação mesmo com a presença de pastagem ou agricultura. Enquanto que as degradadas são as que possuem elevado grau de perturbação, escassez de vegetação e sinais de erosão.

Considerando a baixa precipitação e histórico recente de secas hidrológicas juntamente com o crescimento desordenado que afeta o semiárido brasileiro, é imprescindível o desenvolvimento de pesquisas que evidenciem a análise e recuperação de áreas degradadas como nascentes, especialmente aquelas localizadas em áreas urbanas. Assim como a relação sociedade natureza Silva et al., (2017). E especialmente com a precipitação e os fenômenos que as alteram como o El Niño, Maier et al., 2016, como também as relações estatísticas Silva et al., 2017.

A modelagem da área é essencial para garantir a eficiência e eficácia do projeto de recuperação ambiental, sendo assim, geotecnologias surgem como um grande subsídio para a revitalização. Conforme Rosa (2005), as geotecnologias também conhecidas como geoprocessamento são um conjunto de tecnologias que possuem como objetivo coletar, analisar, processar e ofertar informações georeferenciadas. Entre as geotecnologias destacam-se: cartografia digital, sensoriamento remoto, sistema de posicionamento global e os sistemas de informações geográficas (SIGs). 
O sensoriamento remoto é uma ciência relacionada a obtenção de informações sobre um determinado objeto, área ou fenômeno por meio de dados obtidos por aparelhos distantes do alvo. É uma prática atrativa que diminui custos e fornece uma maior rapidez na obtenção de dados e permite o monitoramento da superfície terrestre possibilitando identificar o feito das ações antrópicas assim como modificações ambientais (Leite et al., 2017).

O presente trabalho teve como objetivo analisar a degradação, a partir de uma modelagem do relevo, da Nascente Vila Maria localizada no munícipio de Garanhuns no estado de Pernambuco.

\section{Material e métodos}

O município de Garanhuns (Figura 1) possui uma área de $458.55 \mathrm{~km}^{2}$ delimitado pelas coordenadas geográficas de: $-8^{\circ} 51^{\prime} 37^{\prime \prime} / 8^{\circ} 55^{\prime} 40^{\prime \prime}$ e $-36^{\circ} 26^{\prime} 06^{\prime \prime}$ / $-36^{\circ} 30^{\prime} 52^{\prime \prime}$.

O sítio urbano de Garanhuns possui elevada amplitude topográfica com média altimétrica de $830 \mathrm{~m}$ e máxima de 1030 m conforme a Administração
Nacional da Aeronáutica e Espaço - NASA (2011). De acordo com o Instituto Nacional de Meteorologia INMET (2013) a região possui um alto índice pluviométrico, com médias mensais de $80 \mathrm{~mm}$. No mês de julho tal índice pode ser superior a $155 \mathrm{~mm}$.

Conforme Rodrigues et al. (2011), o clima de Garanhuns é As' mesotérmico na classificação climática de Köppen-Geiger, com temperatura média anual de 20 ${ }^{\circ} \mathrm{C}$.

Entre 1982 e 2004, a extensão urbana de Garanhuns sofreu um aumento considerável de 76,43 $\mathrm{km}^{2}$ para $150,57 \mathrm{~km}^{2}$ em decorrência do papel de polo regional que o munícipio exerce e pela política de erradicação do café implantada pelo Instituto Brasileiro do Café - IBC (Melo, 2013). A referida erradicação fez com que Garanhuns passasse a receber um contingente populacional de forma repentina sendo aqueles oriundos do campo fixados em áreas de baixo valor comercial como encostas e fundos de vales (Melo e Souza, 2015).

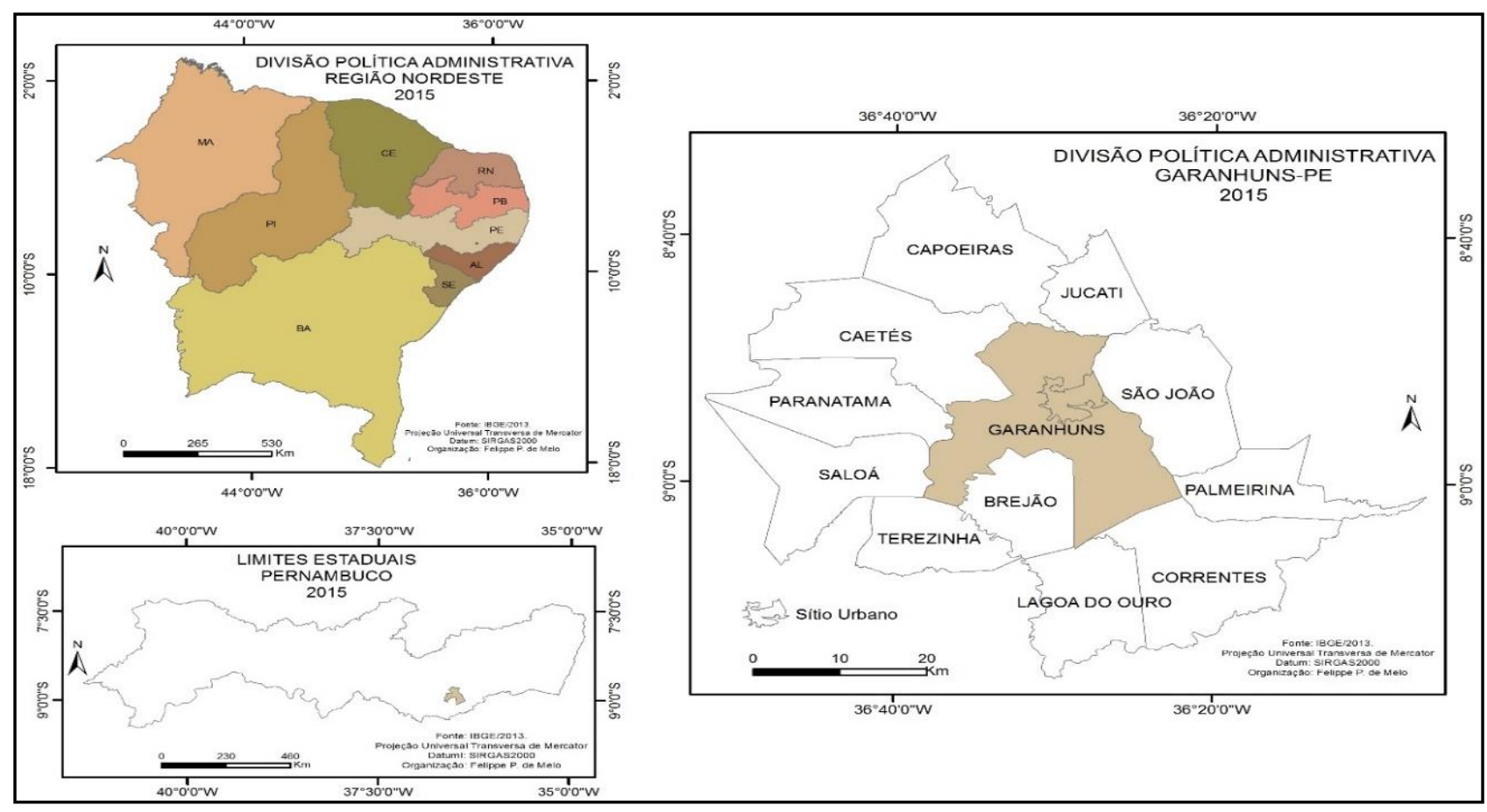

Figura 1 - Localização da área de estudo. Fonte: IBGE (2013).

A partir de 1970, a malha urbana de Garanhuns passou a se expandir com maior intensidade acarretando no surgimento e intensificação de diversos problemas socioambientais, como condições precárias de moradias em áreas de risco e a poluição de nascentes que outrora foram utilizadas para abastecimento da população (Soares et al., 2013).

A falta de planejamento urbano aliada à geomorfologia da região faz com que a população acabe ocupando áreas acidentadas, como as encostas de alta declividade. De acordo com Soares (2015) a Nascente 
Vila Maria está localizada próxima ao centro comercial de Garanhuns e suas adjacências foram ocupadas em virtude da facilidade em s e obter água

abundante e gratuita. Ainda conforme o Autor, a nascente sofre constantemente com o descarte inadequado de esgoto na região e mesmo em face da contaminação o seu fluxo é utilizado para abastecer uma lavanderia comunitária construída na década de 1950 pelo governo municipal.

Conforme Silva (2012) a Nascente Vila Maria sempre foi consagrada como a segunda fonte mais importante da cidade de Garanhuns, superada apenas pela nascente Serra Branca e de acordo com Rego (1987) a qualidade do fluxo contínuo oriundo da Nascente Vila Maria teve uma grande influência na história do município.

Considerando as dificuldades enfrentadas no semiárido, e a condição especial do município de Garanhuns em possuir importantes nascentes e um índice pluviométrico acima da média da região, é de suma importância garantir a integridade desses recursos hídricos e revitalizar os que estiverem degradados com o intuito de fornecer água não somente para Garanhuns, mas também para os municípios adjacentes.

A pesquisa foi realizada em três etapas distintas: Registro fotográfico a partir de visitas técnicas a nascente; Modelagem do relevo da microbacia onde a Nascente Vila Maria está inserida; Análise da evolução do Índice de Vegetação da Diferença Normalizada (NDVI) entre os anos de 2008 e 2018 tendo como referência os tempos chuvosos e secos.

\section{Modelagem do relevo}

Inicialmente, tendo como referência a lavanderia pública da Nascente Vila Maria, foi coletado, no software Google Earth, um retângulo envolvente extenso comprometendo uma grande área ao redor do ponto de referência que por sua vez foi exportado para o software Global Mapper cujo foi possível obter os dados do relevo com resolução de 30 metros do satélite ASTER GDEM v2 elaborado pela NASA (2011).

Os dados da geomorfologia foram processados com o intuito de alterar a projeção para Universal Transversa de Mercator (UTM) e datum para SIRGAS 2000. Posteriormente, os dados foram exportados para o software Surfer, no qual foi possível realizar um delineamento da microbacia da Nascente Vila Maria, assim como obter os seguintes produtos cartográficos: Modelado da área e adjacências; Declividade da superfície e Direcionamento do escoamento superficial.

As informações obtidas na modelagem do relevo da microbacia onde a Nascente Vila Maria está inserida, fornece uma nova dimensão e referência para as discussões em volta do registro fotográfico realizado na visita técnica.

\section{Análise do NDVI}

Índices de vegetação, entre outros métodos, tem sido bastante precisos no monitoramento de mudanças na vegetação. Um dos índices mais utilizado é o NDVI (Nath, 2014). De acordo com Aburas et al. (2015) o índice NDVI é um dos métodos mais significativos de classificação e muito utilizado para detectar alterações na cobertura e ocupação do solo.

Os valores do NDVI podem variar entre -1 e 1, sendo positivos quando os alvos são rochas, solos descobertos e vegetação, por conseguinte são negativos quando o alvo reflete com maior intensidade na banda vermelha em comparação com a banda do infravermelho próximo, algo comum quando o alvo é composto por nuvens, corpos d'água ou neve. Altos valores de NDVI são associados a maiores densidades de vegetação saudável (Cordeiro et al., 2017).

Estudos sobre vegetação saudável vem ganhando mais atenção ao longo do tempo, em virtude de seu papel importante em promover serviços ecossistêmicos (Nouri et al., 2017).

Conforme Durigon et al. (2014) o NDVI pode ser calculado pela Equação 1 elaborada por Tucker (1979) resultando em um valor de -1 até +1 com base no fato de que o NDVI de regiões com grande cobertura vegetal tende a um valor de +1 .

$$
N D V I=\frac{\rho_{N I R}-\rho_{R e d}}{\rho_{N I R}+\rho_{\text {Red }}}
$$

Onde, NDVI é o Índice de Vegetação da Diferença Normalizada; $\rho_{N I R}$ é o valor da banda espectral do infravermelho próximo; $\rho_{\text {Red }}$ é o valor da banda espectral do vermelho.

As informações da banda espectral do vermelho e infravermelho próximo foram obtidas a partir das bandas 4 e 5 dos satélites Landsat 8 e das bandas 3 e 4 do satélite Landsat 5 para os anos de 2008 até 2018 no portal Earth Explorer mantido pela instituição científica Serviço Geológico dos Estados Unidos (USGS).

Considerando a dificuldade em se obter dados que não foram comprometidos pela existência de nuvens, foi selecionado um intervalo temporal de meses conforme os índices pluviométricos de Garanhuns com padrões de maiores e menores precipitações para os dados de cada ano. Em suma, foram coletadas informações da banda espectral do vermelho e infravermelho próximo para os meses de outubro, novembro ou dezembro para representar o período seco e maio, junho ou julho para o período chuvoso, dando 
prioridade ao mês que apresentar a menor incidência de nuvens. Pois, conforme Lira et al. (2006) são nos meses supracitados que ocorrem, respectivamente, a fase seca e a chuvosa no munícipio de Garanhuns. Em anos onde os meses do intervalo temporal supracitado estavam totalmente corrompidos por nuvens, foi selecionado o mês com menor incidência de nuvens mais próximo do intervalo.

A partir dessas informações foi aplicada a Equação 1 para obter os valores médios de NDVI para a área. Todavia, a aplicação das equações foi realizada a partir de um algoritmo elaborado na ferramenta Model Builder no software ArcGIS. Para Cascales et al. (2017) a referida ferramenta permite criar e automatizar fluxos de trabalho através de cadeias de comandos e geoprocessos por intermédio de um banco de dados de entrada.

O algoritmo utilizou como base a ferramenta Raster Calculator e terá como dados de entrada os rasters das bandas espectrais do vermelho e infravermelho que resultará em um raster para o NDVI, o cálculo realizado nesse trâmite será o valor médio para a microbacia. Por conseguinte, o resultado desse procedimento foi comparado com a precipitação acumulada que outrora fora obtida no portal do INMET (2019).

\section{Resultados e discussão}

A partir das visitas ao local, constatou-se a existência de indicadores de processos erosivos intensos
(Figura 2A) que formaram uma voçoroca considerável na região da nascente. Conforme Soares (2015) essa voçoroca possui 300 metros de comprimento com pouco mais de sete metros de profundidade, e teve origem em função do descarte inadequado de esgoto pluvial no topo da vertente. A visita técnica constatou que o dispositivo de drenagem (canaleta) responsável pelo descarte foi desativado (Figura 2B) recentemente pela atual gestão pública.

Contudo, somente cessar o descarte inadequado não é o suficiente, o governo municipal não implementou medidas para recuperação do dano causado. Em consequência, ao longo dos anos o estado de má gestão da problemática irá agravar a degradação hídrica da nascente, de modo a contribuir para a sua sedimentação. Além disso, não há um monitoramento da microbacia visando impedir que as residências despejem seus resíduos diretamente na vertente.

O fluxo da nascente é coletado por uma galeria que o direciona ao longo da vertente, havendo uma bifurcação para alimentação da lavanderia comunitária (Figura 2C e 2D). O fluxo é então conectado ao esgoto pluvial da região e descartado no fundo da vertente. Observa-se que a água da nascente não é adequadamente aproveitada pelo município e conforme Soares (2015) o seu fluxo, acaba sendo contaminado pelo esgoto pluvial agravado pela ausência de saneamento no município que encoraja os moradores a conectarem o esgoto residencial na rede pluvial.

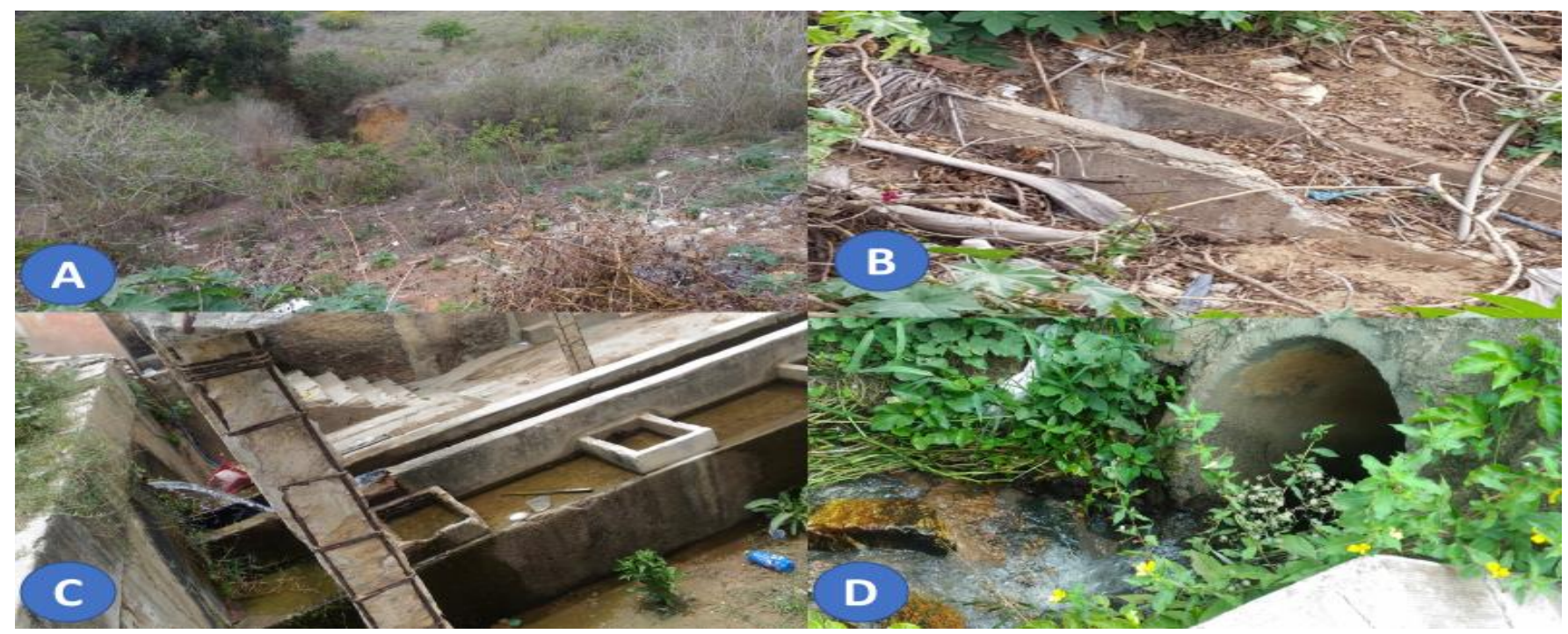

Figura 2 - Voçoroca, canaleta desativada, lavanderia comunitária, esgoto pluvial. Fonte: Acervo dos Autores, 2019.

Em relação ao regime de água, a partir das visitas ao local foi possível constatar, conforme Calheiros (2009), que a Nascente Vila Maria é classificada como perene, em outras palavras significa dizer que ela possui fluxo contínuo. Também é importante contextualizar a relação dos fenômenos 
climáticos com a precipitação, Rodrigues et al., (2018), uma vez que o clima pode alterar a perenidade de um rio. A Figura 3 consiste em um modelado da microbacia da Nascente Vila Maria, contendo indicadores para a localização da lavanderia pública do local e para o direcionamento do escoamento superficial da microbacia. $\mathrm{O}$ modelo indicou que a área superficial da microbacia é de aproximadamente $3,34 \mathrm{~km}^{2}$.

A Tabela 1 consiste nos resultados do mapeamento da declividade do modelado da microbacia da Nascente Vila Maria classificado conforme EMBRAPA (2013).

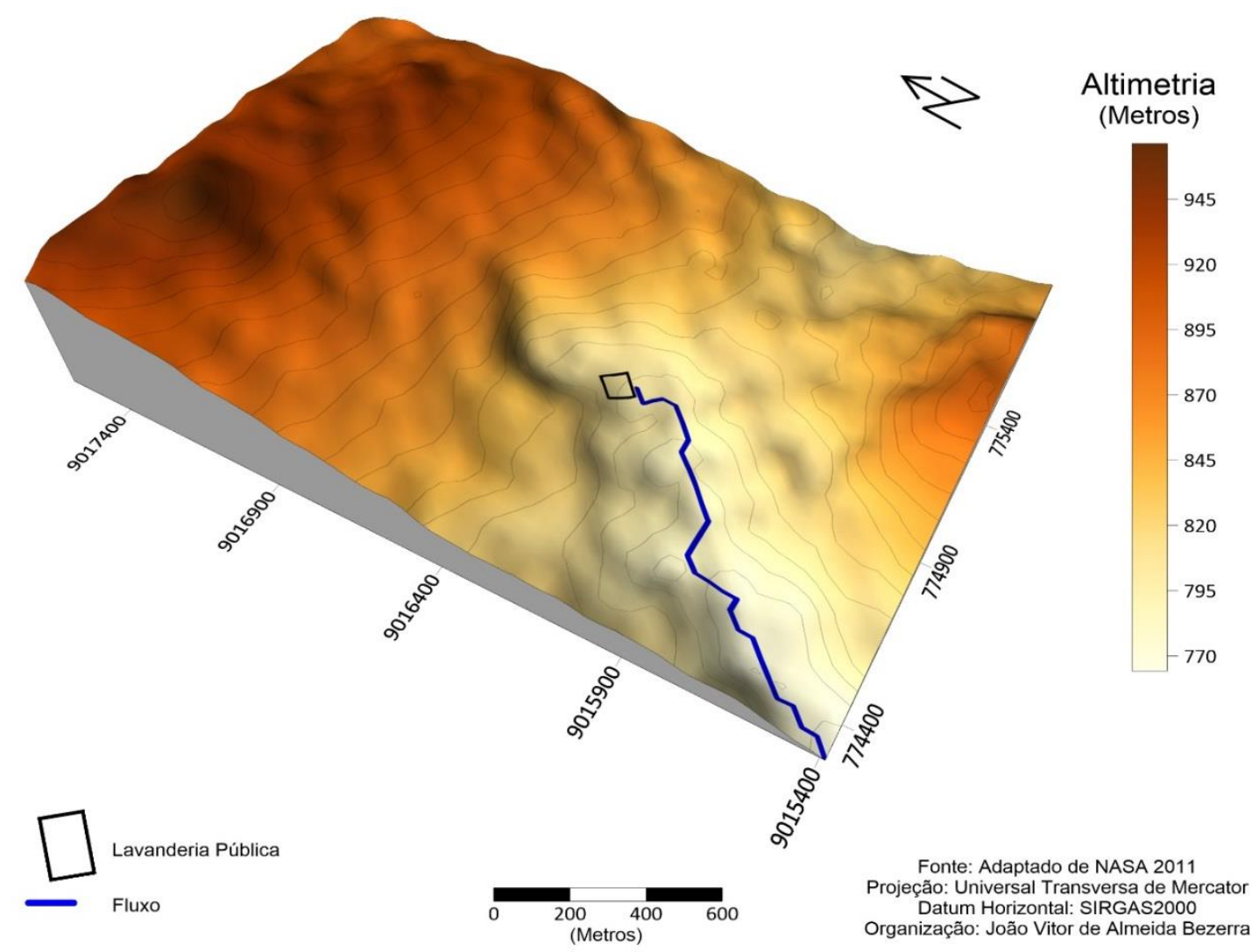

Figura 3 - Modelado da microbacia da Nascente Vila Maria, Garanhuns-PE. Fonte: Adaptado de NASA (2011).

Tabela 1 - Classificação da declividade da microbacia da Nascente Vila Maria conforme EMBRAPA (2013).

\begin{tabular}{ccc}
\hline Declividade & Relevo & \% da Área \\
\hline $0-3$ & Pleno & 9,92 \\
$3-8$ & Suave Ondulado & 54,47 \\
$8-20$ & Ondulado & 35,52 \\
$20-45$ & Forte Ondulado & 0,08 \\
\hline
\end{tabular}

Fonte: Adaptado de NASA, 2011.

A declividade média obtida pela modelagem do relevo foi de $7,16 \%$ e conforme a Tabela 1 a região é considerada suave ondulada. Porém, observa-se que existe uma parcela substancial de relevo ondulado. Para Mendes (2006) áreas com alta declividade são mais afetadas pela erosão, em decorrência do aumento da velocidade de escoamento superficial.

A infiltração de água oriunda do escoamento superficial aumenta a poropressão do solo em áreas de alta declividade e diminui sua estabilidade (Haugen, 2017). Essa diminuição da estabilidade, aumenta a susceptibilidade do relevo inclinado de sofrer movimentos de massa que por sua vez contribuem para a sedimentação da nascente podendo contaminar e/ou alterar a vazão da nascente. 
A inclinação da microbacia contribui para que a nascente possua uma alta velocidade de escoamento que junto ao regime contínuo de fluxo, garante um volume abundante e constante na lavandeira pública da região.

A Figura 4 consiste no resultado da análise do NDVI para a região da microbacia entre os anos de 2008 e 2018. Os dados de 2012 não foram utilizados na análise em virtude do alto grau de corrupção das imagens por nuvens.

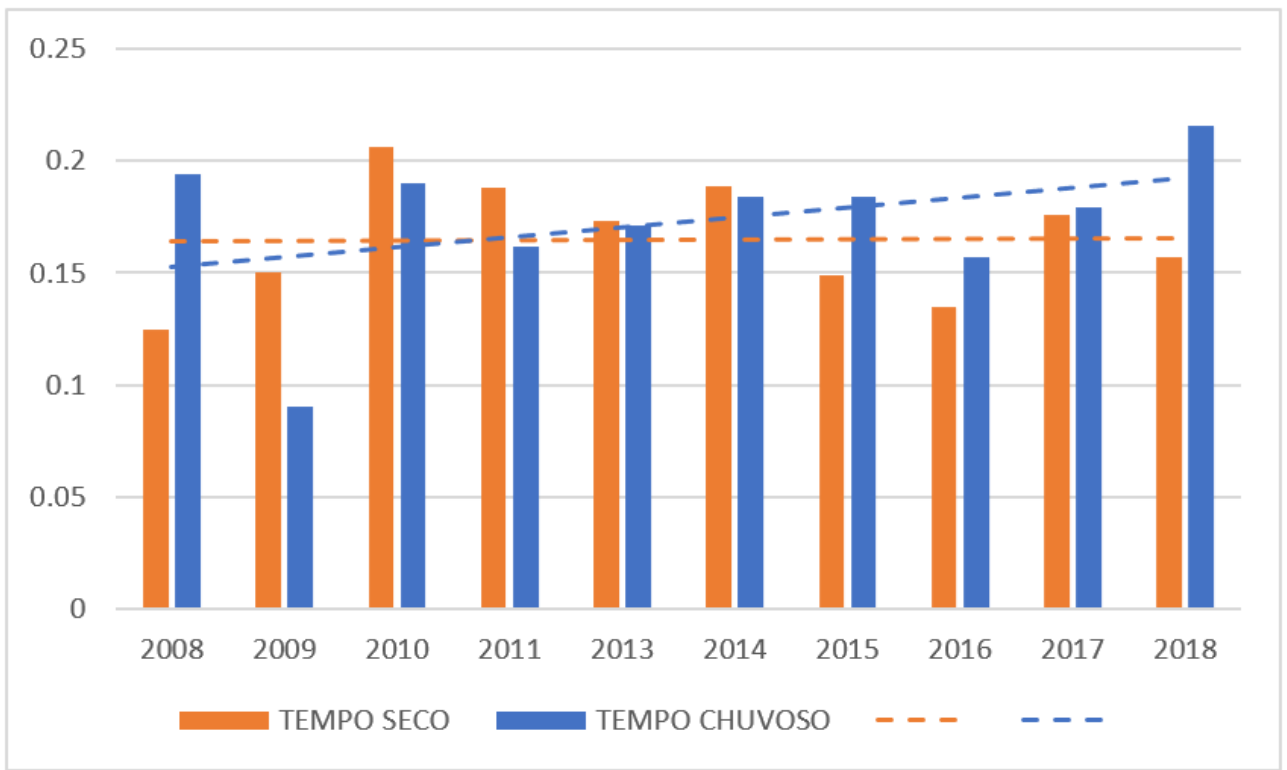

Figura 4 - Índice de Vegetação da Diferença Normalizada (NDVI) da microbacia da Nascente Vila Maria, GaranhunsPE. Fonte: Adaptado de Landsat 5 e Landsat 8.

Observa-se na Figura 4 valores médios baixos calculados para o NDVI. A microbacia da Nascente Vila Maria é uma área urbanizada cuja expansão é realizada a partir da remoção da cobertura vegetal para possibilitar assentamentos. Esse crescimento explica os baixos valores médios do NDVI que em tempos de seca se mantiveram constante entre 2008 e 2018. Porém, a linha de tendência aponta para um crescimento da média durante os tempos chuvosos.

A nascente Vila Maria possui regime de fluxo contínuo, ou seja, não depende diretamente da precipitação para garantir o seu fluxo. Esse fato, contribui para que o NDVI em tempos de seca seja constante, pois a nascente irá fornecer um abastecimento permanente para a cobertura vegetal da região.

$\mathrm{O}$ crescimento desordenado, além do aumento da precipitação, pode ser um dos motivos para o NDVI apresentar esse comportamento de alta nos tempos chuvosos ao longo dos anos. A medida em que a poligonal urbana expande, a demanda por serviços de drenagem superficial aumenta de forma considerável. Porém, os sistemas não são implementados de forma correta e acabam despejando o fluxo em sentido as vertentes da microbacia. Na época chuvosa, há um aumento da demanda do sistema de drenagem superficial e consequentemente haverá um volume maior de água percorrendo as vertentes tendo em vista que o sistema atual despeja diretamente nelas. Essa intensificação pode ser evidenciada pelos vestígios de processos erosivos no local, bem como na voçoroca visível na Figura 2.

A Figura 5 consiste em uma comparação do NDVI médio com a precipitação acumulada para o intervalo de tempo chuvoso.

Observa-se na Figura 5 uma tendência de queda na precipitação acumulada do intervalo temporal chuvoso (maio, junho e julho) entre 2010 e 2018. Contudo, o NDVI médio continuou crescendo ao longo dos anos. Esse fato reforça o argumento da expansão urbana estar contribuindo para a cobertura vegetal da microbacia ao realizar o descarte inadequado do esgoto pluvial.

Conforme Kaspersen et al. (2015) a extensão e localização de zonas impermeáveis nas áreas urbanas afetam de forma considerável o volume e a velocidade do escoamento superficial durante chuvas intensas. Em suma, o efeito da impermeabilização causado pela expansão da poligonal urbana também pode ter contribuído para o aumento das médias de NDVI nas épocas chuvosas ao intensificar o escoamento superficial.

Considerando que conforme Durigon et al. (2014) valores de NDVI próximos a 1 indicam cobertura vegetal densa, os valores médios obtidos para a área da 
microbacia indicam uma baixa densidade de vegetação. Para Schor e Gray (2007) a cobertura vegetal pode promover um aumento da resistência do solo e trazer grandes benefícios para as encostas ao protege-las contra a erosão.

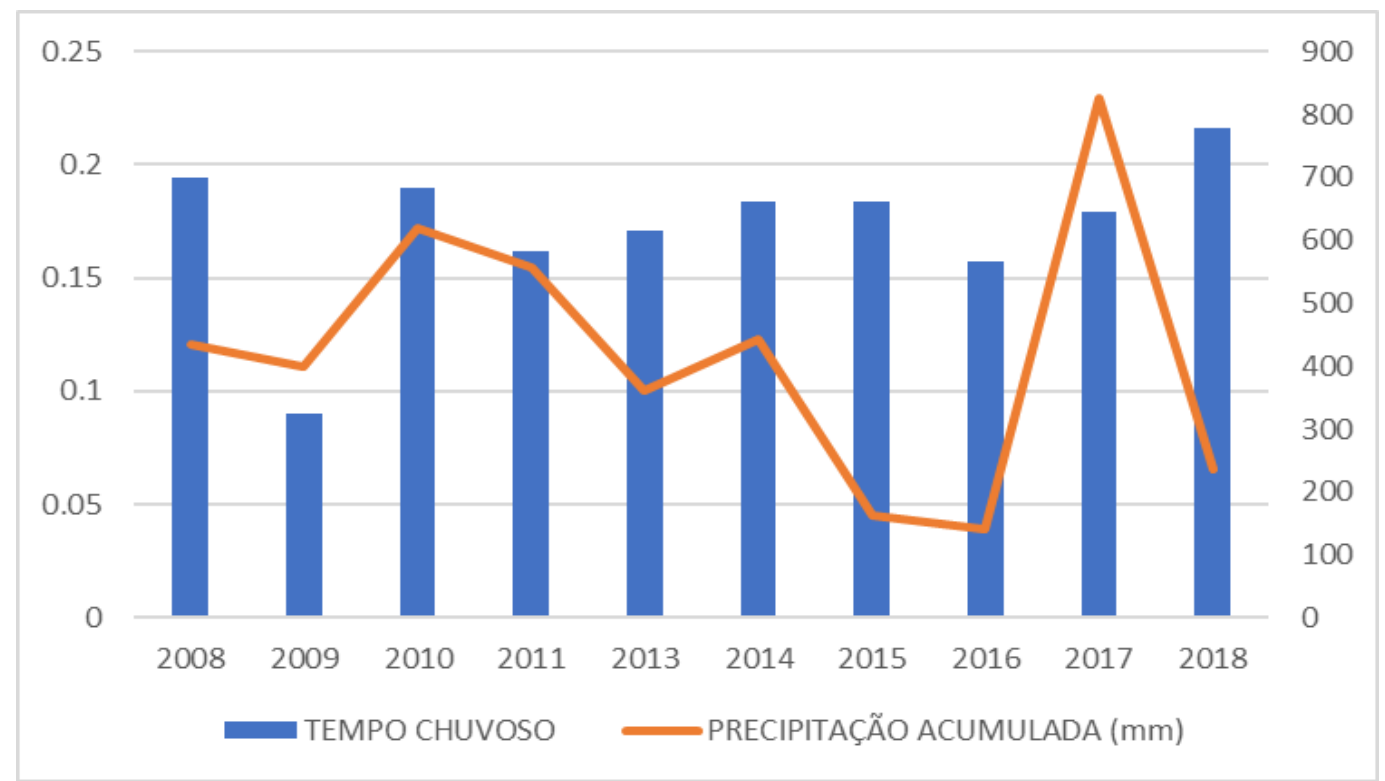

Figura 5 - Índice de Vegetação da Diferença Normalizada (NDVI) e a precipitação acumulada do período chuvoso da microbacia da Nascente Vila Maria, Garanhuns-PE. Fonte: Adaptado de INMET (2019); Landsat 5 e Landsat 8.

Melo (2013) aponta que a poligonal urbana de Garanhuns está se expandido em direção as encostas instáveis do seu relevo em virtude da falta de áreas adequadas para assentamento. Para Soares e Troleis (2018) a expansão urbana em Garanhuns ocorre majoritariamente de forma não planejada frequentemente desrespeitando a legislação e os aspectos ambientais fundamentais, tal como a declividade das encostas e as áreas das nascentes. A expansão urbana de Garanhuns sobre as áreas de encostas, ocorreu em concomitância a um forte evento de estiagem no ano de 1982, e conduziu a tipos de ações antrópicas extremamente nocivas aos sistemas naturais do período (Azambuja e Corrêa, 2015).

A dinâmica de distribuição da população no espaço urbano é regida fundamentalmente pelo "valor do solo". O espaço urbano de Garanhuns é fortemente condicionado à sua morfologia, relevo, solo e eixos viários. Esse fato leva as populações de baixa renda a se instalarem em locais de qualidade inferior, seja em relação às edificações, seja na infraestrutura instalada (Azambuja e Corrêa, 2015).

Em suma, a degradação das nascentes urbanas em Garanhuns se caracteriza como um cenário de risco geomorfológico, onde a população mais carente, por falta de escolha, ocupa vertentes instáveis e no processo de assentamento acabam removendo a cobertura vegetal e despejando seus resíduos ao longo da vertente. Essas ações, além de contaminarem a nascente e possibilitarem a propagação de doenças de

veiculação hídrica, contribuem para a intensificação dos processos erosivos aumentando o risco de movimentos de massa que por sua vez causam sedimentação nas nascentes, comprometendo assim a sua vazão.

A declividade acentuada e o NDVI obtido para a microbacia da Nascente Vila Maria, com valores médios de baixa magnitude, agem como indicadores que vão de acordo com a fragilidade social complexa supracitada. Isso se deve ao fato de que os valores confirmam uma impermeabilização do solo em locais de encosta.

Vale salientar que embora o NDVI seja um bom indicador da cobertura vegetal, ele por si só não garante uma análise real do fenômeno. Além disso, somente o aumento da cobertura vegetal não é sinônimo da mitigação do risco geomorfológico, principalmente quando se considera que o aumento do NDVI da microbacia em estudo, pode estar atrelado à condicionais nocivas ao meio ambiente como o descarte inadequado dos sistemas de drenagem pluvial.

\section{Conclusões}


A atuação de polo regional da cidade de Garanhuns se tornou cenário de um crescimento urbano desordenado, esse desenvolvimento insustentável também não é compatível com o desenvolvimento geomorfológico adequado a região. Esse fato é evidenciado pelas extensas comunidades que se alojaram em locais de risco os quais deveriam ser zona de proteção ambiental, por exemplo, as adjacências das nascentes.

Os resultados classificaram a Nascente Vila Maria como perene em função do seu fluxo contínuo, com relevo suave ondulado. A degradação da nascente foi constatada em virtude da presença de sinais de erosão e elevado grau de perturbação em suas poligonais, e essa causa se deve a ocupação inadequada de suas adjacências pela população marginalizada. Por conseguinte, o crescimento do NDVI médio para tempos chuvosos atesta uma perturbação no ecossistema da nascente.

A ocupação desordenada das adjacências da Nascente Vila Maria, a geomorfologia da região e a ausência de medidas que visem remediar a degradação sofrida por ela, configura um ambiente de risco geomorfológico impulsionado pela intensificação dos processos erosivos.

Ademais, constatou-se o mal aproveitamento do fluxo da Nascente Vila Maria que acaba sendo integrado ao esgoto pluvial e descartado de maneira inadequada no fundo da vertente, contribuindo para o risco supracitado e criando um ambiente propicio à propagação de doenças de veiculação hídrica.

\section{Agradecimentos}

Os Autores agradecem a Coordenação de Aperfeiçoamento de Pessoal de Nível Superior (CAPES) cujo apoio, a partir do financiamento de bolsa de mestrado, foi essencial para a elaboração dessa pesquisa.

\section{Referências}

Aburas, M.M., Abdullaha, S.H., Ramlia, M.F., Ash'aar, Z.H., 2015. Measuring land cover change in Seremban, Malaysia using NDVI index. Procedia Environmental Sciences 30, 238-243.

Azambuja, R.N., Corrêa, A.C.B., 2015. Geomorfologia e áreas de expansão urbana do município de Garanhuns-PE: uma abordagem espaço-temporal dos eventos morfodinâmicos para o planejamento territorial. Geo UERJ 27, 202-233.

BRASIL, 2012. Lei $\mathrm{n}^{0}$ 12.651, de 25 de maio.
Calheiros, R.O. et al., 2009. Preservação e Recuperação das Nascentes de Água e de Vida. 2 ed. SMA, São Paulo.

Carmo, L.G., Felippe, M.F., Magalhães Junior, A.P., 2014. Áreas de preservação permanente no entorno de nascentes: conflitos, lacunas e alternativas da legislação ambiental brasileira. Boletim Goiano de Geografia 34, 275-293.

Cordeiro, A.P.A., Berlato, M.A., Fontana, D.C., Melo, R.W., Shimabukuro, Y.E., Claudimar Sidnei Fior, C.S., 2017. Regiões homogêneas de vegetação utilizando a variabilidade do NDVI. Ciência Florestal 27, 883-896.

Cascales, M.I., Llorens, J.L. S., Giner, J.J., 2017. Cálculo de escenarios de daños sísmicos en la Comunidad Valenciana utilizando model builder (ArcGIS). Geogaceta 62, 67-70.

Durigon, V.L., Carvalho, D.F., Antunes, M.A.H., Oliveira, P.T.S., Fernandes, M.M., 2014. NDVI time series for monitoring RUSLE cover management factor in a tropical watershed. International Journal of Remote Sensing 35, 441-453.

EMBRAPA. Empresa Brasileira de Pesquisa Agropecuária, 2013. Sistema Brasileiro de Classificação de Solos. 3. ed. EMBRAPA, Brasília.

Felippe, M.F., Magalhães Junior, A.P., 2013. Conflitos conceituais sobre nascentes de cursos d'água e propostas de especialistas. GeoGrafias 9, 70-81.

Felippe, M.F., Magalhães Junior, A.P., 2012. Impactos ambientais macroscópicos e qualidade das águas em nascentes de parques municipais em Belo HorizonteMG. GeoGrafias 15, 8-23.

Haugen, B.D., 2017. A design method for landslide surface water drainage control. Environmental \& Engineering Geoscience 23, 275-289.

IBGE. Instituto Brasileiro de Geografia e Estatística, 2013. Malhas Digitais. Disponível: http://downloads.ibge.gov.br/downloads_geociencia s.htm. Acesso 10 jan. 2016.

INMET. Instituto Nacional de Meteorologia, 2019. Banco de Dados Meteorológicos para Ensino e Pesquisa.

Disponível: http://www.inmet.gov.br/portal/index.php?r=bdmep /bdmep. Acesso: 17 maio 2019.

Kaspersen, P.S., Ravn, N.H., Arnbjerg-Nielsen, K., Madsen, H., Drews, M., 2015. Influence of urban land cover changes and climate change for the exposure of European cities to flooding during highintensity precipitation. PIAHS 370, 21-27.

Leite, A.P., Santos, G.R., Santos, J.E.O., 2017. Análise temporal dos índices de vegetação NDVI e SAVI na estação experimental de Itatinga utilizando imagens 
Landsat 8. Revista Brasileira de Energias Renováveis 6, 606-623.

Lira, V.M., Oliveira, F.M., Dantas, R.T., Souza, W.M., 2006. Alterações da precipitação em municípios do estado de Pernambuco. Engenharia Ambiental: Pesquisa e Tecnologia 3, 52-61.

Lozinski, M.A., Balbinot, R., Venâncio, D., Oliveira Filho, P.C., Schirmer, W.N., 2010. Diagnóstico das áreas de preservação permanente de nascentes na área urbana do município de Irati-PR. Floresta 40, 63-70.

Maier, E. L. B., Costi, J., Barreira, S., Simoôes J.A. 2016. Precipitação na América do Sul: médias climáticas e padrões da variabilidade no período entre 1979 e 2008. Revista Brasileira de Geografia Física 09, 032-046. DOI :https://doi.org/10.26848/rbgf.v9.1.p032-046

Mendes, C.A.R., 2006. Erosão superficial em encosta íngreme sob cultivo perene e com pousio no município de Bom Jardim - RJ. Tese (Doutorado). Rio de Janeiro, UFRJ.

Melo, F.P., 2013. Modelo de uso e ocupação da paisagem no município de Garanhuns - PE. Reget 10, 2198-2207.

Melo, F.P., Souza, R.M., 2015. Mapeamento geomorfológico da fragilidade ambiental do sítio urbano de Garanhuns - PE. Nativa 3, 263-267.

NASA. National Aeronautics and Space Administration, 2011. ASTER GDEM v2. Disponível: https://gdex.cr.usgs.gov/gdex/. Acesso: 12 out. 2016.

Nath, B., 2014. Quantitative assessment of forest cover change of a part of Bandarban Hill tracts using NDVI techniques. Journal of Geosciences and Geomatics 2, 21-27.

Nouri, H., Anderson, S., Sutton, P., Beecham, S., Nagler, P., Jarchow, C.J., Roberts, D.A., 2017. NDVI, scale invariance and the modifiable areal unit problem: An assessment of vegetation in the Adelaide Parklands. Science of The Total Environment 584-585, 11-18.

Ooi, M.K.J. 2015. Seed bank dynamics and climate change in semi-arid ecosystems: a focus on physically dormant species. Revista Brasileira de Geografia Física 08, 651-659.

Pinto, L.V.A., 2003. Caracterização física da sub-bacia do Ribeirão Santa Cruz, Lavras, MG, e propostas de recuperação de suas nascentes. Dissertação (Mestrado). Lavras, UFLA.

Rego, A.S., 1987. Os Aldeões de Garanhuns. Centro de Estudos da História Municipal, Recife.

Rodrigues, B.M., Arcoverde, G.B., Antonino, A.C.D., Santos, M.G., 2011. Water relations in physic nut according to climatic seasonality, in semiarid conditions. Pesquisa Agropecuária Brasileira 46, 1112-1115.

Rodrigues, L.O., Souza, W.M., Costa, V.S.O., Pereira, M.LT, 2018. Influência dos eventos de El Niño e La Niña no regime de precipitação do Agreste de Pernambuco. Revista Brasileira de Geografia Física 10, 1995-2009.

Rosa, R., 2005. Geotecnologias na geografia aplicada. Revista do Departamento de Geografia 16, 81-90.

Schor, H.J., Gray, D.H., 2007. Landforming: an environmental approach to hillside development, mine reclamation and watershed restoration. Wiley, Hoboken.

Silva, A.S., 2012. Territorialidades em torno das águas: discursividade e práticas de apropriação e uso dos mananciais em Garanhuns/PE. Tese (Doutorado). Recife, UFPE.

Silva, M. R. , Moura, F. P. Jardim, C.H. 2017. O diagrama de caixa (Box Plot) aplicado à análise da distribuição temporal das chuvas em Januária, Belo Horizonte e Sete Lagoas, Minas Gerais-Brasil. Revista Brasileira de Geografia Física 10, 023-040. DOI: https://doi.org/10.5935/1984-2295.20170003

Soares, A.B., 2015. Análise da problemática socioambiental das nascentes urbanas no município de Garanhuns - PE. Dissertação (Mestrado). Natal, UFRN.

Soares, A.B., Santos, C.C., Cavalcanti, M.A., 2013. Problemática socioambiental urbana na nascente Pau Amarelo em Garanhuns - PE. Revista Brasileira de Geografia Física 6, 1140-1157.

Soares, A.B., Troleis, A.L., 2018. A expansão urbana de Garanhuns-PE entre 1811 e 2016 e suas implicações socioambientais. Revista Movimentos Sociais e Dinâmicas Espaciais 7, 185-209. 